\title{
Formulation and Evaluation of Sustained Release Matrix Tablets of Repaglinide
}

\author{
Kambham Venkateswarlu \\ Faculty of Pharmacy, Department of Pharmaceutics, JNTUA-Oil Technological and Pharmaceutical Research \\ Institute, Ananthapuramu, Andhra Pradesh-515001, India
}

Received: December 12, 2015; Accepted: February 14, 2016; Published (Web): February 17, 2016

\begin{abstract}
The aim of present investigation was to formulate and evaluate the sustained release matrix tablets of Repaglinide (RPGN). These matrix tablets were prepared by wet granulation method using synthetic and natural polymers like HPMC K4M, HPMC 100M and Guar gum (GG), Carrageenan (CG), respectively. Invitro drug release studies were performed by USP dissolution apparatus type-II (paddle method) using $0.1 \mathrm{~N}$ $\mathrm{HCl}$ buffer and $\mathrm{pH} 6.8$ phosphate buffer for $12 \mathrm{~h}$. Amongst all the 12 formulations, formulation F12 showed maximum drug release of $97.9 \%$ for $12 \mathrm{~h}$ study. It was observed from the kinetic studies that all the formulations followed first order kinetics and particularly the drug release from its dosage form was fickian diffusion (F9, F12), non-fickian diffusion (F1-F8, F10-F11). Formulation F12 was subjected to stability studies and confirmed that formulation F12 was stable upto the period of 1 month.
\end{abstract}

Key words: Matrix tablets, natural polymers, repaglinide, synthetic polymers, wet granulation

\section{Introduction}

The conventional dosage forms such as tablets and capsules are the major oral preparations and have wide acceptance up to 50-60\% of total dosage forms. Solid dosage forms are popular because of ease of administration, accurate dosage, self-medication, pain avoidance and most importantly the patient compliance in last two decades (Gujar et al., 2014).

Repaglinide i.e. (+) 2-ethoxy-4(2((3-methyl-1-(2(1-piperidinyl) phenyl)- butyl) amino)-2-oxoethyl) benzoic acid (Harika et al., 2013) is an oral antihyperglycemic agent used for the treatment of non insulin dependent diabetes mellitus (NIDDM). It belongs to the meglitinide class of short acting insulin secretagogues, which act by binding to the $\beta$ cells of the pancreas to stimulate the insulin release (Dasharath et al., 2012; Venkataramudu et al., 2012). Considerable research had been done on the drug RPGN for sustained release and from the literature, it was found that they were developed bioadhesive buccal drug delivery system (Dasharath et al., 2012), effect of Hydroxy propyl- $\beta$-cyclodextrin on sustained release bioadhesive buccal tablets (Harika et al., 2013), gastroretentive nanoparticles (Gujar et al., 2014), matrix systems of Repaglinide using natural polymers (Venkataramudu et al., 2012) and synthetic polymers (Joshi et al., 2012; Barot et al., 2014).

The most commonly using method of modulating the drug release is matrix system (Venkateswarlu and Shanthi, 2012) and an effort was therefore made to develop simple and effective sustained release Repaglinide tablets using a polymer matrix system. From the previous studies, they have developed matrix system using natural polymers like Pectin, Guar gum, Xanthan gum and retarded upto $10 \mathrm{~h}$ only (Venkataramudu et al., 2012) but incase of synthetic polymers they have retarded upto $12 \mathrm{~h}$ (Barot et al., 2014). Hence, in the present study, an attempt has been made to develop sustained release matrix tablets of Repaglinide using the synthetic polymers like HPMC K4M, HPMC 100M and natural polymers like Gaur gum, Carrageenan gum and fixed to retard the drug release up to $12 \mathrm{~h}$.

Correspondence to: Kambham Venkateswarlu, Contact No: +91-9441701016; E-mail: k.v.reddy9441701016@ gmail.com 


\section{Materials and Methods}

Materials: RPGN was obtained from Active Pharma labs, India and HPMC K4M and HPMC 100M from Yarrow Chemicals, India, GG from Crystal Colloids Ltd., India, CG and PVP from Active Pharma labs, India, Magnesium stearate (MS) and Talc from Merck specialties Pvt. Ltd., India, Lactose from Chemdyes Corporation, India.

Drug excipient compatibility studies: The pure drug and its physical mixtures were subjected to IR spectral studies using FTIR spectrophotometer (Bruker, USA) in the wave number region from $4000 \mathrm{~cm}^{-1}$ to $400 \mathrm{~cm}^{-1}$. The spectra obtained for pure drug and the physical mixtures were compared.

Table 1. Preparation of RPGN matrix tablets.
Formulation development: Tablets were prepared by wet granulation method using different synthetic and natural polymers like HPMC K4M, HPMC 100M and Guar gum, carrageenan, respectively. Half of the amount of the required quantity of all the ingredients except MS, talc mentioned in table 1 was taken into a mortar and damp mass was prepared by using isopropoyl alcohol as granulating agent. This damp mass was passed through sieve \#12 and the granules were dried in an oven at $60{ }^{\circ} \mathrm{C}$ for about $30 \mathrm{~min}$ and then they were passes through sieve \#16. To this remaining half of the quantity of all ingredients and required quantity of MS, talc were added, mixed uniformly. From this mixture, required quantity of the tablet weight was taken and compressed to the tablet using RIMEK rotary tablet punching machine.

\begin{tabular}{lcccccccccccc}
\hline \multicolumn{1}{c}{ Ingredients } & F1 & F2 & F3 & F4 & F5 & F6 & F74 & F8 & F9 & F10 & F11 & F12 \\
\hline RPGN & 10 & 10 & 10 & 10 & 10 & 10 & 10 & 10 & 10 & 10 & 10 & 10 \\
HPMC K4M & 5 & 10 & 15 & - & - & - & - & - & - & - & - & - \\
HPMC 100M & - & - & - & 5 & 10 & 15 & - & - & - & - & - & - \\
GG & - & - & - & - & - & - & 5 & 10 & 15 & - & - & - \\
CG & - & - & - & - & - & - & - & - & - & 5 & 10 & 15 \\
Lactose & 130 & 125 & 120 & 130 & 125 & 120 & 130 & 125 & 120 & 130 & 125 & 120 \\
MS & 2 & 2 & 2 & 2 & 2 & 2 & 2 & 2 & 2 & 2 & 2 & 2 \\
Talc & 2 & 2 & 2 & 2 & 2 & 2 & 2 & 2 & 2 & 2 & 2 & 2 \\
PVP & 1 & 1 & 1 & 1 & 1 & 1 & 1 & 1 & 1 & 1 & 1 & 1 \\
Total weight (mg/tablet) & 150 & 150 & 150 & 150 & 150 & 150 & 150 & 150 & 150 & 150 & 150 & 150 \\
\hline
\end{tabular}

Evaluation studies: The precompression parameters like Bulk density and Tapped density (Shah et al., 1997), Angle of repose (Cooper and Gunn, 1986), Compressibility index and Hausner's ratio (USP, 2000) were performed for powder blend and the postcompression parameters like friability, hardness, thickness, weight variation (Banker and Anderson, 1987) were evaluated for the formulated tablets.

Drug Content (Assay): The drug content of the matrix tablets was determined according to in-house standards and it meets the requirements, if the amount of the active ingredient in each of the 3 tested tablets lies within the range of $90 \%$ to $110 \%$ of the standard amount. Three tablets were weighed and taken into a mortar and crushed into fine powder. An accurately weighed portion of the powder equivalent to average weight of three tablets of RPGN was transferred into a $100 \mathrm{ml}$ volumetric flask containing $\mathrm{pH} 6.8$ Phosphate buffer solution and the volume was made up to the mark. From this, $10 \mathrm{ml}$ solution was taken and shaken by mechanical means using centrifuge at $3000 \mathrm{rpm}$ for $30 \mathrm{~min}$. Then it was filtered through whatman filter paper. From this resulted solution, $1 \mathrm{ml}$ was taken, diluted to $10 \mathrm{ml}$ with $\mathrm{pH} 6.8$ Phosphate buffer and absorbance was measured against blank using UVVisible spectrophotometer (UV-1800 Spectrophotometer, Shimadzu, Japan) at $237 \mathrm{~nm}$.

In vitro drug release studies: Drug release was assessed by dissolution test and which has been performed by USP type-II dissolution apparatus 
(Electro lab TDT-06N USP dissolution apparatus, India) at $50 \mathrm{rpm}$ using $0.1 \mathrm{~N} \mathrm{HCl}$ buffer and $\mathrm{pH} 6.8$ phosphate buffer for $12 \mathrm{~h}$ and temperature was maintained at $37{ }^{\circ} \mathrm{C} \pm 0.5{ }^{\circ} \mathrm{C}$. An aliquot $(5 \mathrm{~mL})$ was withdrawn at specific time intervals and replaced with the same volume of pre warmed $\left(37^{\circ} \mathrm{C} \pm 0.5^{\circ} \mathrm{C}\right)$ fresh dissolution medium and it was suitably diluted, analyzed by UV-Visible spectrophotometer at $237 \mathrm{~nm}$.

Kinetic analysis of dissolution data: The in-vitro drug release data was subjected to various mathematical models for determining the drug release kinetics and drug release mechanism from its dosage form (Dash, 2010).

Stability studies: In the present study, the stability study was performed as per the ICH guidelines at 30 ${ }^{\circ} \mathrm{C} / 60 \% \mathrm{RH}$ and $40{ }^{\circ} \mathrm{C} / 75 \% \mathrm{RH}$ for the selected formulation for about 1 month. After specified time intervals, parameters like hardness, drug content and dissolution were evaluated (Kulkarni, 2014; Kanvide and Kulkarni, 2005; Mohrle, 1980).

\section{Results and Discussion}

Compatibility studies: On comparison of pure drug FTIR spectra with the spectra of physical mixtures, it was observed that there is no appearance of new peaks and shifting of already existed peaks indicates absence of drug excipients incompatibility (Tables 2, 3, 4 and 5 \& Figures 1, 2, 3 and 4).

Micromeritic study: Before preparing the matrix tablets of RPGN, the powder mass was evaluated for flow properties. Hausner's ratio was found to be less than 1.25, indicates good flowability of RPGN powder blends. Carr's index was found in the range of 11.62 to 16.62, indicates that the RPGN powder blends had shown good to fair flowability. Angle of repose was ranged from $31^{\circ}$ to $35^{\circ}$, indicates that the RPGN blends possessing good flow properties (Table 6).

Post compression parameters: All the prepared tablets of RPGN were evaluated for weight variation. The weight of all the tablets was found to be uniform with low values of standard deviation and fall within the prescribed pharmacopoeial limits of $\pm 10 \%$. The hardness of the tablet formulations was found to be in

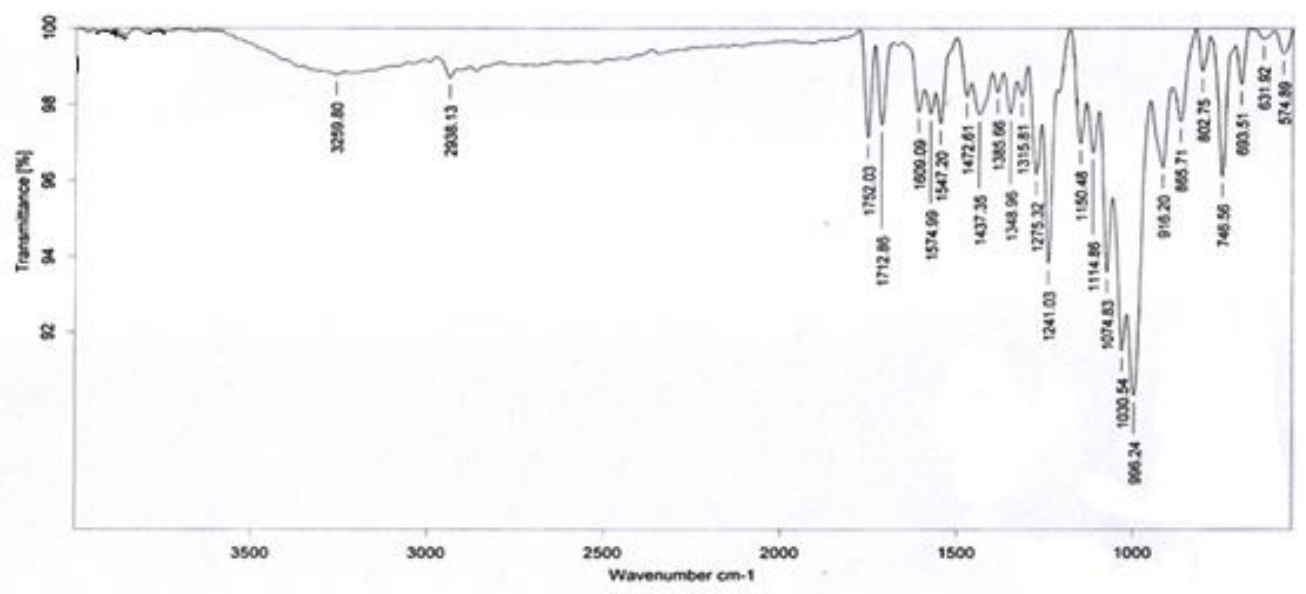

Figure 1. FTIR spectra of pure RPGN.

Table 2. Interpretation of IR spectra of pure RPGN.

\begin{tabular}{llcl}
\hline Sample & \multicolumn{2}{c}{ Wave number $\left(\mathrm{cm}^{-1}\right)$} & \multicolumn{1}{c}{ Functional group } \\
\cline { 2 - 3 } & Range & Observed & \\
\hline & $\sim 3300$ & 3250 & $-\mathrm{C}=\mathrm{C}-\mathrm{H}$ (str) \\
& $2960-2850$ & 2938 & $-\mathrm{C}-\mathrm{H}(\mathrm{str})$ \\
& $\sim 1788$ & 1752 & $-\mathrm{C}=\mathrm{O}$ cyclobutanone (str) \\
& $1610-1550$ & 1547 & $-\mathrm{C}=\mathrm{O}$ carboxylate anion (str) \\
& $1550-1510$ & 1542 & $-\mathrm{N}-\mathrm{H} 2^{0}$ amide \\
\hline
\end{tabular}




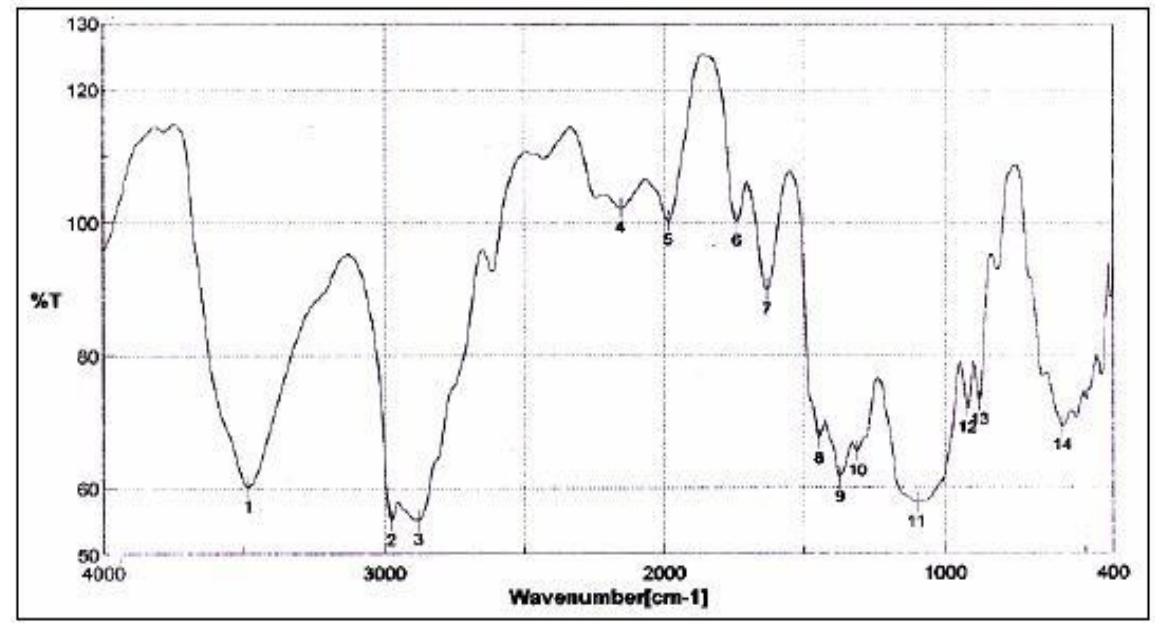

Figure 2. FTIR spectra of RPGN + HPMC.

Table 3. Interpretation of IR spectra of RPGN + HPMC.

\begin{tabular}{|c|c|c|c|}
\hline \multirow[t]{2}{*}{ Sample } & \multicolumn{2}{|c|}{ Wave number $\left(\mathrm{cm}^{-1}\right)$} & \multirow[t]{2}{*}{ Functional group } \\
\hline & Range & Observed & \\
\hline \multirow{5}{*}{ RPGN + HPMC } & $\sim 3300$ & 3360 & $-\mathrm{C}=\mathrm{C}-\mathrm{H}(\mathrm{str})$ \\
\hline & $2960-2850$ & 2940 & $-\mathrm{C}-\mathrm{H}(\mathrm{str})$ \\
\hline & $\sim 1788$ & 1762 & $-\mathrm{C}=\mathrm{O}$ cyclobutanone $(\mathrm{str})$ \\
\hline & $1610-1550$ & 1550 & $-\mathrm{C}=\mathrm{O}$ carboxylate anion $(\mathrm{str})$ \\
\hline & $1550-1510$ & 1542 & $-\mathrm{N}-\mathrm{H} 2^{\circ}$ amide \\
\hline
\end{tabular}

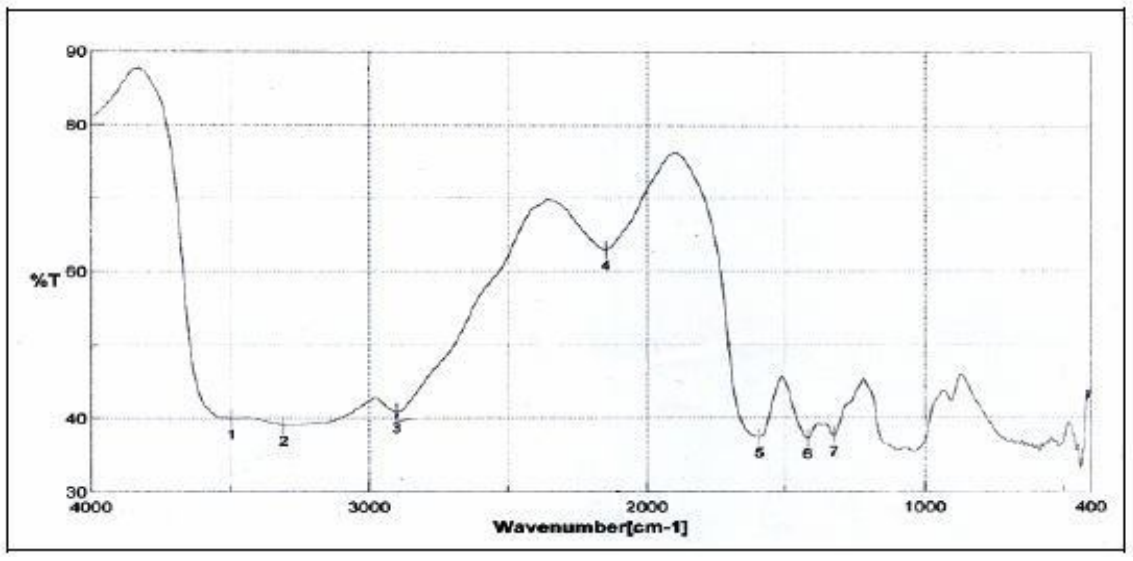

Figure 3. FTIR spectra of RPGN + GG.

Table 4. Interpretation of IR spectra of RPGN + GG.

\begin{tabular}{|c|c|c|c|}
\hline \multirow[t]{2}{*}{ Sample } & \multicolumn{2}{|c|}{ Wave number $\mathrm{cm}^{-1}$} & \multirow[t]{2}{*}{ Functional group } \\
\hline & Range & Observed & \\
\hline \multirow{5}{*}{$\mathrm{RPGN}+\mathrm{GG}$} & $\sim 3300$ & 3280 & $-\mathrm{C}=\mathrm{C}-\mathrm{H}$ (str) \\
\hline & $2960-2850$ & 2880 & $-\mathrm{C}-\mathrm{H}(\mathrm{str})$ \\
\hline & $\sim 1788$ & 1762 & $-\mathrm{C}=\mathrm{O}$ cyclobutanone $(\mathrm{str})$ \\
\hline & $1610-1550$ & 1550 & $\mathrm{C}=\mathrm{O}$ carboxylate anion $(\mathrm{str})$ \\
\hline & $1550-1510$ & 1543 & -N-H $2^{0}$ amide \\
\hline
\end{tabular}




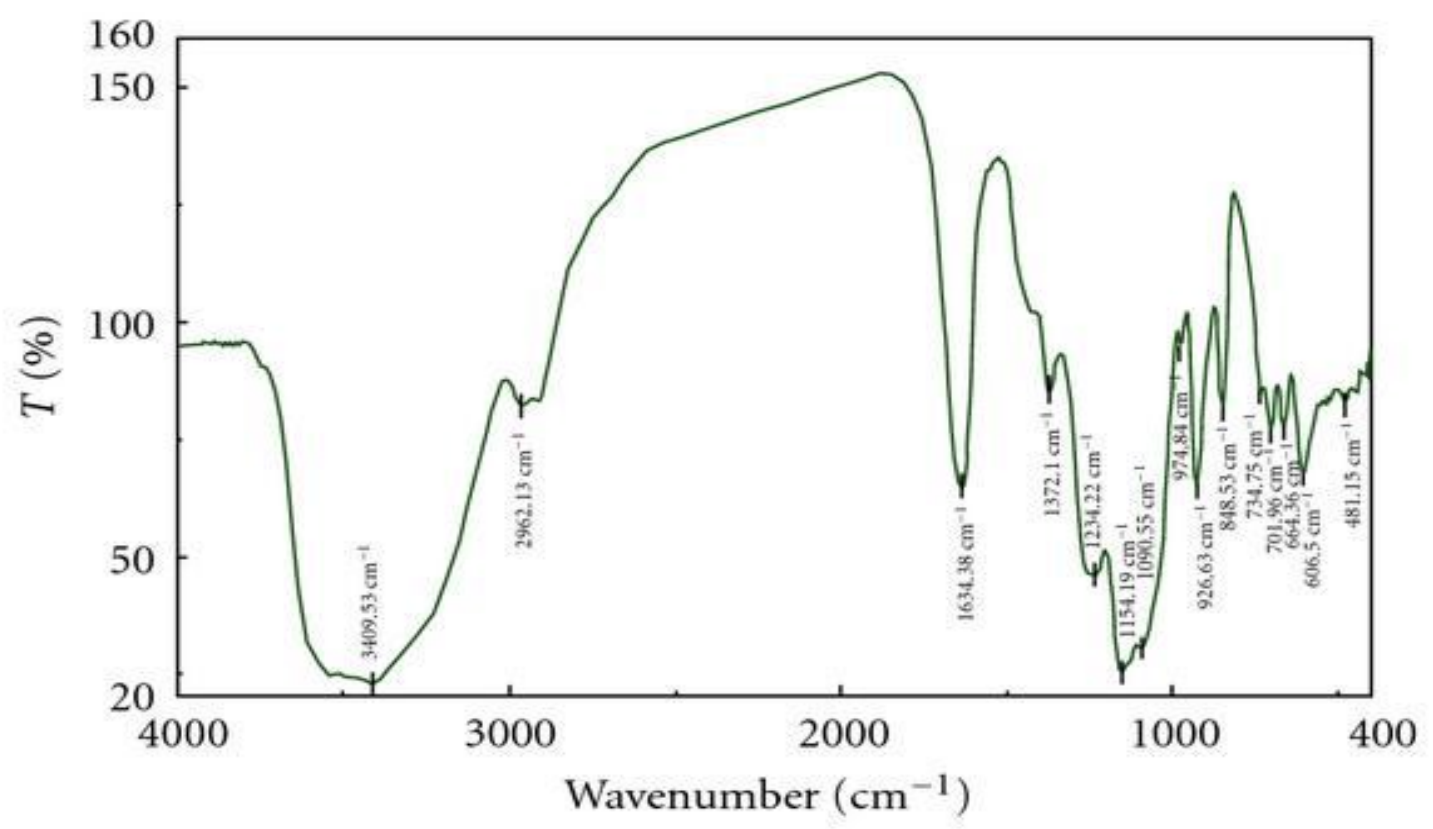

Figure 4. FTIR spectra of RPGN + CG.

Table 5. Interpretation of IR spectra of RPGN + CG.

\begin{tabular}{llcl}
\hline Sample & \multicolumn{2}{c}{ Wave number $\mathrm{cm}^{-1}$} & \multicolumn{1}{c}{ Functional group } \\
\cline { 2 - 3 } & \multicolumn{2}{c}{ Range } & Observed \\
\hline \multirow{3}{*}{ RPGN + CG } & $\sim 3300$ & 3409 & -C = C-H (str) \\
& $2960-2850$ & 2962 & $-\mathrm{C}-\mathrm{H}$ (str) \\
& $\sim 1788$ & 1634 & $-\mathrm{C}=\mathrm{O}$ cyclobutanone (str) \\
\hline
\end{tabular}

Table 6. Precompression studies.

\begin{tabular}{cccccc}
\hline $\begin{array}{c}\text { Formulation } \\
\text { Code }\end{array}$ & $\begin{array}{c}\text { Bulk density } \\
(\mathrm{gm} / \mathrm{ml})\end{array}$ & $\begin{array}{c}\text { Tapped density } \\
(\mathrm{gm} / \mathrm{ml})\end{array}$ & $\begin{array}{c}\text { Carr's index } \\
(\%)\end{array}$ & $\begin{array}{c}\text { Hausner's } \\
\text { ratio }\end{array}$ & Angle of repose $(\theta)$ \\
\hline F1 & $0.55 \pm 0.12$ & $0.65 \pm 0.89$ & 12.2 & $1.21 \pm 0.87$ & t23.45 \pm 0.0002 \\
F2 & $0.54 \pm 0.31$ & $0.62 \pm 0.781$ & 13.1 & $1.22 \pm 0.67$ & $19.65 \pm 0.0055$ \\
F3 & $0.56 \pm 0.41$ & $0.64 \pm 0.65$ & 14.5 & $1.23 \pm 0.45$ & $22.35 \pm 0.0063$ \\
F4 & $0.54 \pm 0.54$ & $0.63 \pm 0.51$ & 14.1 & $1.24 \pm 0.39$ & $20.69 \pm 0.0074$ \\
F5 & $0.50 \pm 0.84$ & $0.64 \pm 0.45$ & 12.3 & $1.22 \pm 0.59$ & $20.82 \pm 0.0041$ \\
F6 & $0.53 \pm 0.78$ & $0.64 \pm 0.32$ & 13.4 & $1.23 \pm 0.43$ & $20.72 \pm 0.0056$ \\
F7 & $0.51 \pm 0.97$ & $0.67 \pm 0.21$ & 14.6 & $1.24 \pm 0.48$ & $20.89 \pm 0.0049$ \\
F8 & $0.52 \pm 0.64$ & $0.62 \pm 0.91$ & 14.7 & $1.21 \pm 0.57$ & $20.76 \pm 0.0058$ \\
F9 & $0.56 \pm 0.53$ & $0.61 \pm 0.87$ & 12.3 & $1.22 \pm 0.56$ & $22.61 \pm 0.0041$ \\
F10 & $0.52 \pm 0.72$ & $0.66 \pm 0.74$ & 13.3 & $1.21 \pm 0.42$ & $22.32 \pm 0.0039$ \\
F11 & $0.51 \pm 0.89$ & $0.62 \pm 0.68$ & 14.6 & $1.24 \pm 0.32$ & $24.64 \pm 0.0087$ \\
F12 & $0.57 \pm 0.99$ & $0.68 \pm 0.54$ & 15.1 & $1.25 \pm 0.12$ & $25.83 \pm 0.0094$ \\
\hline
\end{tabular}

Results were expressed in Avg \pm SD (n=3) 
Table 7. Post compression studies.

\begin{tabular}{ccccc}
\hline Formulations & Weight variation $(\%)$ & Hardness $\left(\mathrm{kg} / \mathrm{cm}^{2}\right)$ & Thickness $(\mathrm{mm})$ & Friability $(\%)$ \\
\hline F1 & $1.44 \pm 0.21$ & $5.12 \pm 0.124$ & $3.221 \pm 0.0038$ & $0.321 \pm 0.21$ \\
F2 & $1.41 \pm 0.24$ & $5.23 \pm 0.25$ & $3.342 \pm 0.0041$ & $0.421 \pm 0.32$ \\
F3 & $1.40 \pm 0.31$ & $5.27 \pm 0.27$ & $3.351 \pm 0.0042$ & $0.432 \pm 0.12$ \\
F4 & $1.41 \pm 0.34$ & $5.31 \pm 0.31$ & $3.367 \pm 0.0044$ & $0.471 \pm 0.41$ \\
F5 & $1.42 \pm 0.36$ & $5.26 \pm 0.33$ & $3.371 \pm 0.0045$ & $0.512 \pm 0.54$ \\
F6 & $1.46 \pm 0.41$ & $5.32 \pm 0.34$ & $3.372 \pm 0.0047$ & $0.653 \pm 0.32$ \\
F7 & $1.47 \pm 0.45$ & $5.48 \pm 0.35$ & $3.381 \pm 0.0041$ & $0.782 \pm 0.56$ \\
F8 & $1.45 \pm 0.35$ & $5.44 \pm 0.36$ & $3.383 \pm 0.0042$ & $0.861 \pm 0.37$ \\
F9 & $1.44 \pm 0.63$ & $5.55 \pm 0.33$ & $3.394 \pm 0.0048$ & $0.751 \pm 0.87$ \\
F10 & $1.48 \pm 0.55$ & $5.46 \pm 0.38$ & $3.395 \pm 0.0044$ & $0.573 \pm 0.67$ \\
F11 & $1.46 \pm 0.45$ & $5.47 \pm 0.36$ & $3.397 \pm 0.0043$ & $0.524 \pm 0.94$ \\
F12 & $1.47 \pm 0.56$ & $5.49 \pm 0.37$ & $3.397 \pm 0.0045$ & $0.681 \pm 0.65$ \\
\hline
\end{tabular}

Results were expressed in Avg \pm SD ( $n=3)$

the range of 4 to $5 \mathrm{~kg} / \mathrm{cm}^{2}$. The friability values were found to be in the range of 0.50 to $0.75 \%$. All the formulations showed less than $1 \%$ friability ensuring that the tablets were mechanically stable (Table 7).

Drug content: The low values of standard deviation indicate uniform drug content within the tablets. The percent drug content of all the tablets was found to be in the range of 97.3 to 101.1 percent (which was within the acceptable limits of $\pm 5 \%$ ).

In vitro dissolution study: Formulations F1, F2 and F3 were prepared by using $5 \mathrm{mg}, 10 \mathrm{mg}$ and $15 \mathrm{mg}$ of HPMC K4M and the drug release was found to be $74.3 \%, 82.3 \%$ and $87.5 \%$ within $6 \mathrm{~h}, 7 \mathrm{~h}, 8 \mathrm{~h}$, respectively. Formulations F4, F5 and F6 were prepared by using $5 \mathrm{mg}, 10 \mathrm{mg}$ and $15 \mathrm{mg}$ of HPMC $100 \mathrm{M}$ and the drug release was found to be $83.6 \%, 87.3 \%$ and
92.3\% within 7 h, 8 h, 9 h, respectively. Formulations F7, F8 and F9 were prepared by using $5 \mathrm{mg}, 10 \mathrm{mg}$ and $15 \mathrm{mg}$ of $\mathrm{GG}$ and the drug release was found to be $88.5 \%, 91.5 \%$ and $93.6 \%$ within $9 \mathrm{~h}$ respectively. Formulations F10, F11 and F12 were prepared by using $5 \mathrm{mg}, 10 \mathrm{mg}$ and $15 \mathrm{mg}$ of CG and the drug release was found to be $93.2 \%, 95.2 \%$ and $97.5 \%$ respectively. The dissolution rate was found to be increased linearly with the increase in concentration of polymer i.e. the polymer concentration is directly proportional to the drug release rate. Amongst all the formulations, Tablets prepared with $\mathrm{CG}$ showed sustained release of drug upto $12 \mathrm{~h}$ especially F11 and F12 but the formulation F12 showed maximum cumulative percent drug release (C\%DR) than F11(Table 8).

Table 8. In-vitro drug release studies of RPGN tablets (F1-F12).

\begin{tabular}{|c|c|c|c|c|c|c|c|c|c|c|c|c|}
\hline $\begin{array}{l}\text { Time } \\
\text { (h) }\end{array}$ & $\mathrm{F} 1$ & $\mathrm{~F} 2$ & F3 & F4 & F5 & F6 & F7 & F8 & F9 & F10 & F11 & $\mathrm{F} 12$ \\
\hline 0 & 0 & 0 & 0 & 0 & 0 & 0 & 0 & 0 & 0 & 0 & 0 & 0 \\
\hline 1 & $22.6 \pm 0.21$ & $26.9 \pm 0.32$ & $29.4 \pm 0.44$ & $25.1 \pm 0.54$ & $29.8 \pm 0.64$ & $33.1 \pm 0.51$ & $27.1 \pm 0.44$ & $31.5 \pm 0.46$ & $36.2 \pm 0.15$ & $29.6 \pm 0.53$ & $33.2 \pm 0.64$ & $37.5 \pm 0.51$ \\
\hline 2 & $31.4 \pm 0.12$ & $35.2 \pm 0.71$ & $41.2 \pm 0.61$ & $36.5 \pm 0.63$ & $41.2 \pm 0.57$ & $46.7 \pm 0.47$ & $38.3 \pm 0.12$ & $41.3 \pm 0.75$ & $45.3 \pm 0.74$ & $40.3 \pm 0.22$ & $47.8 \pm 0.73$ & $51.3 \pm 0.47$ \\
\hline 3 & $46.1 \pm 0.47$ & $51.2 \pm 0.54$ & $54.2 \pm 0.81$ & $48.7 \pm 0.42$ & $52.2 \pm 0.49$ & $57.2 \pm 0.58$ & $49.3 \pm 0.26$ & $53.3 \pm 0.94$ & $59.4 \pm 0.85$ & $52.4 \pm 0.62$ & $57.4 \pm 0.49$ & $59.5 \pm 0.58$ \\
\hline 4 & $53.2 \pm 0.57$ & $62.2 \pm 0.21$ & $67.5 \pm 0.85$ & $57.5 \pm 0.35$ & $61.2 \pm 0.55$ & $68.1 \pm 0.62$ & $59.4 \pm 0.53$ & $61.8 \pm 0.59$ & $66.2 \pm 0.26$ & $60.7 \pm 0.35$ & $66.2 \pm 0.99$ & $69.5 \pm 0.62$ \\
\hline 5 & $66.4 \pm 0.77$ & $72.3 \pm 0.58$ & $76.5 \pm 0.63$ & $69.6 \pm 0.58$ & $72.3 \pm 0.61$ & $75.2 \pm 0.74$ & $71.3 \pm 0.85$ & $76.7 \pm 0.16$ & $79.2 \pm 0.47$ & $72.2 \pm 0.58$ & $76.1 \pm 0.61$ & $79.4 \pm 0.74$ \\
\hline 6 & $74.3 \pm 0.73$ & $78.4 \pm 0.52$ & $81.1 \pm 0.32$ & $77.8 \pm 0.61$ & $81.7 \pm 0.72$ & $83.5 \pm 0.87$ & $79.4 \pm 0.16$ & $83.2 \pm 0.27$ & $86.2 \pm 0.78$ & $81.7 \pm 0.61$ & $83.2 \pm 0.72$ & $86.3 \pm 0.87$ \\
\hline 7 & $74.3 \pm 0.59$ & $82.6 \pm 0.91$ & $85.6 \pm 0.41$ & $83.6 \pm 0.55$ & $86.8 \pm 0.81$ & $88.8 \pm 0.92$ & $82.2 \pm 0.47$ & $85.2 \pm 0.18$ & $89.2 \pm 0.29$ & $85.3 \pm 0.74$ & $87.2 \pm 0.81$ & $89.2 \pm 0.92$ \\
\hline 8 & $74.6 \pm 0.28$ & $82.2 \pm 0.38$ & $87.3 \pm 0.98$ & $83.2 \pm 0.43$ & $87.3 \pm 0.93$ & $90.4 \pm 0.88$ & $85.3 \pm 0.34$ & $88.3 \pm 0.93$ & $90.3 \pm 0.86$ & $87.4 \pm 0.43$ & $89.4 \pm 0.39$ & $91.4 \pm 0.68$ \\
\hline 9 & $74.7 \pm 0.99$ & $82.5 \pm 0.85$ & $87.6 \pm 0.24$ & $83.5 \pm 0.71$ & $87.1 \pm 0.65$ & $92.7 \pm 0.22$ & $88.5 \pm 0.17$ & $91.5 \pm 0.56$ & $93.6 \pm 0.25$ & $93.2 \pm 0.71$ & $92.1 \pm 0.65$ & $95.2 \pm 0.52$ \\
\hline 10 & $74.3 \pm 0.56$ & $82.7 \pm 0.81$ & $87.4 \pm 0.53$ & $83.1 \pm 0.68$ & $87.4 \pm 0.81$ & $92.3 \pm 0.39$ & $88.4 \pm 0.93$ & $91.2 \pm 0.84$ & $93.4 \pm 0.93$ & $93.8 \pm 0.98$ & $95.2 \pm 0.48$ & $97.6 \pm 0.39$ \\
\hline 12 & $74.0 \pm 0.87$ & $82.3 \pm 0.52$ & $87.3 \pm 0.75$ & $83.8 \pm 0.66$ & $87.3 \pm 0.41$ & $92.8 \pm 0.66$ & $88.1 \pm 0.77$ & $91.6 \pm 0.49$ & $93.1 \pm 0.64$ & $93.3 \pm 0.57$ & $95.4 \pm 0.46$ & $97.9 \pm 0.46$ \\
\hline
\end{tabular}


Kinetics study of RPGN formulations (F1-F12): Invitro drug release data of all the sustained release formulations was subjected to goodness of fit test by linear regression analysis according to the zero order and first order kinetic equations and Higuchi's and Korsmeyer-Peppas models to ascertain the mechanism of drug release. The results of linear regression analysis including regression coefficients were summarized in table 9. From this regression coefficient data, it can be seen that all the formulations have displayed first order release kinetics (' $\mathrm{r}^{2}$ ', values in the range of 0.900 to 0.965). From Higuchi and Peppas data, it was evident that the drug was released from its dosage form by nonfickian diffusion mechanism in the case of formulations F1-F8 and F10-F11 but formulations F9 and F12 showed fickian diffusion mechanism (Table 9).

Table 9. Release kinetics data of all the formulations.

\begin{tabular}{|c|c|c|c|c|c|}
\hline \multirow[t]{2}{*}{ Formulation code } & Zero order & First order & Higuchi & Peppas & \multirow[t]{2}{*}{ Drug release mechanism } \\
\hline & $\mathrm{R}^{2}$ & $\mathrm{R}^{2}$ & $\mathrm{R}^{2}$ & $\mathrm{n}$ & \\
\hline $\mathrm{F} 1$ & 0.977 & 0.978 & 0.970 & 0.681 & Non-fickian \\
\hline $\mathrm{F} 2$ & 0.948 & 0.992 & 0.974 & 0.681 & Non-fickian \\
\hline F3 & 0.905 & 0.992 & 0.989 & 0.552 & Non-fickian \\
\hline $\mathrm{F} 4$ & 0.966 & 0.985 & 0.984 & 0.653 & Non-fickian \\
\hline F5 & 0.928 & 0.985 & 0.992 & 0.550 & Non-fickian \\
\hline F6 & 0.881 & 0.994 & 0.992 & 0.485 & Non-Fickian \\
\hline F7 & 0.918 & 0.991 & 0.989 & 0.569 & Non-fickian \\
\hline F8 & 0.99 & 0.986 & 0.987 & 0.521 & Non-fickian \\
\hline F9 & 0.873 & 0.985 & 0.987 & 0.446 & Fickian \\
\hline F10 & 0.921 & 0.979 & 0.993 & 0.546 & Non-fickian \\
\hline F11 & 0.862 & 0.996 & 0.987 & 0.464 & Non-Fickian \\
\hline F12 & 0.791 & 0.991 & 0.959 & 0.397 & Fickian \\
\hline
\end{tabular}

Table 10. Evaluation of formulated F12 tablets after 1 month of stability study.

\begin{tabular}{lcc}
\hline Parameters & $30{ }^{\circ} \mathrm{C} / 60 \% \mathrm{RH}$ & $40{ }^{\circ} \mathrm{C} / 75 \% \mathrm{RH}$ \\
\hline Hardness $\left(\mathrm{kg} / \mathrm{cm}^{2}\right)$ & 4.5 & 4.6 \\
Drug content $(\%)$ & 96.43 & 97.58 \\
\hline
\end{tabular}

Table 11. C\% DR of F12 formulation subjected to stability studies at $30{ }^{\circ} \mathrm{C} / 60 \% \mathrm{RH}$ and $40{ }^{\circ} \mathrm{C} / 75 \% \mathrm{RH}$ for $1 \mathrm{month}$.

\begin{tabular}{cccc}
\hline \multirow{2}{*}{$\begin{array}{c}\text { Time } \\
\text { intervals }(\mathrm{h})\end{array}$} & \multicolumn{3}{c}{$\mathrm{C} \% \mathrm{DR}$ of F12 } \\
\cline { 2 - 4 } & $\begin{array}{c}30{ }^{\circ} \mathrm{C} / 60 \% \mathrm{RH} \\
(\text { After 1 month) }\end{array}$ & $\begin{array}{c}4{ }^{\circ} \mathrm{C} / 75 \% \mathrm{RH} \\
\text { (After } 1 \text { month) }\end{array}$ & $\begin{array}{c}\mathrm{F} 12 \\
\left(\text { Dissolution study- } 37^{\circ} \mathrm{C} \pm 0.5{ }^{\circ} \mathrm{C}\right)\end{array}$ \\
\hline 0 & 0 & 0 & 0 \\
1 & $38.2 \pm 0.43$ & $39.8 \pm 0.74$ & $37.5 \pm 0.51$ \\
2 & $52.4 \pm 0.76$ & $53.3 \pm 0.31$ & $51.3 \pm 0.47$ \\
3 & $60.5 \pm 0.58$ & $62.8 \pm 0.39$ & $59.5 \pm 0.58$ \\
4 & $69.9 \pm 0.49$ & $68.6 \pm 0.43$ & $69.5 \pm 0.62$ \\
5 & $80.4 \pm 0.43$ & $80.8 \pm 0.53$ & $79.4 \pm 0.74$ \\
6 & $87.3 \pm 0.78$ & $86.3 \pm 0.79$ & $86.3 \pm 0.87$ \\
7 & $89.9 \pm 0.39$ & $90.2 \pm 0.91$ & $89.2 \pm 0.92$ \\
8 & $91.7 \pm 0.45$ & $92.5 \pm 0.69$ & $91.4 \pm 0.68$ \\
9 & $96.4 \pm 0.57$ & $94.2 \pm 0.61$ & $95.2 \pm 0.52$ \\
10 & $97.7 \pm 0.81$ & $96.8 \pm 0.46$ & $97.6 \pm 0.39$ \\
11 & $97.9 \pm 0.84$ & $98.5 \pm 0.51$ & $97.7 \pm 0.57$ \\
12 & $98.7 \pm 0.73$ & $99.7 \pm 0.49$ & $97.9 \pm 0.46$ \\
\hline
\end{tabular}


Stability studies: After stability study period of 1 month, the selected F12 tablets were evaluated for the post compression parameters like hardness, drug content and in-vitro drug release. From the results, it was evident that there was no significant change occurs in the above parameters. The C\% DR of F12 was compared with the C\% DR after stability studies and it was observed that there was no significant change occurs in C\% DR (Tables 10 and 11).

\section{Conclusion}

It could be concluded from the results, that the tablets consist of the polymer carrageenan showed sustained release upto $12 \mathrm{~h}$, especially the formulation F12. In the previous studies, they have retarded the drug release up to $10 \mathrm{~h}$ using natural polymer Pectin (Venkataramudu et al., 2012) but in this study, extended the drug release up to $12 \mathrm{~h}$ using the natural polymer Carrageenan gum. Kinetic studies confirmed that all the formulations follows first order kinetics and mechanism involved in drug release from its dosage form was fickian diffusion (F9, F12), non-fickian diffusion (F1-F8, F10-F11). Formulation F12 was subjected to stability studies and confirmed that the formulation F12 stable upto the period of 1 month. Success of the in-vitro drug release studies recommends the product for further in-vivo studies, which may improves the patient compliance.

\section{References}

Banker, G.S. and Anderson, N.R.I. 1987. In: Lachman, L., Liberman, H.A. and Kanig, J.L. (Eds.). The Theory and Practice of Industrial Pharmacy, $3^{\text {rd }}$ ed. Mumbai: Varghese Publishing House, pp. 293-299.

Barot, N., Darshan, M. and Praful, D.B. 2014. Formulation, development and evaluation of sustained release matrix tablets of repaglinide. J. Appl. Pharm. Sci. 3, 370-396.

Cooper, J. and Gunn, C. 1986. Powder flow and compaction. In: Carter, S.J. (Eds.), Tutorial Pharmacy. New Delhi: CBS Publishers and Distributors, pp. 211-233.
Dash, S., Murthy, P.N., Nath, L. and Chowdhury, P. 2010. Kinetic modelling on drug release from controlled drug delivery systems. Acta. Pol. Pharm. 67, 217-223.

Dasharath, M.P., Pratik, M.S. and Chhagan, N.P. 2012. Formulation and evaluation of bioadhesive buccal drug delivery of repaglinide tablets. Asian. J. Pharm. 6, 171179.

Gujar, K.N., Nemmaniwar, S.B., Kulkarni, N.B. and Jamkar, P.M. 2014. Formulation and evaluation of gastroretentive nanoparticles of Repaglinide. Int. J. Pharm. Sci. Nanotech. 7, 2363-2370.

Harika, K., Sunitha, K., Pavan Kumar, P. and Madhusudan Rao, Y. 2013. Influence of Hydroxypropyl- $\beta$ cyclodextrin on Repaglinide release from sustained release bioadhesive buccal tablets. Asian J Pharm. Clin. Res. 6, 184-190.

Joshi, J., Lata, B. and Sachin, K. 2012. Formulation and evaluation of solid matrix tablets of Repaglinide. Der. Pharm. Sin. 3, 598-603.

Kulkarni, G.T., Gowthamarajan, K. and Suresh, B. 2004. Stability testing of pharmaceutical products: An overview. Indian J. Pharm. Edu. Res. 38, 194-202.

Kanvide, S.A. and Kulkarni, M.S. 2005. Stability of oral solid dosage forms: A Global Perspective. Pharma. Times 37, 9-15.

Mohrle, R. 1980. Effervescent tablets. In: Lieberman, H.A. and Lachman, L. (Eds). Pharmaceutical dosage formsTablets. New York: Mercel Dekker, pp. 232-246.

Shah, D., Shah, Y. and Rampradhan, M. 1997. Development and evaluation of controlled release diltiazem hydrochloride microparticles using cross-linked poly (vinyl alcohol). Drug Dev. Ind. Pharm. 23, 567-574.

Venkataramudu, T., Firoz, S., Chandramouli, Y., Vikram, A., Divya, S.K. and Murali, K.T. 2012. Design and characterization sustained release matrix tablets of repaglinide using naturalpolymers. Int. J. Pharm. 2, 7385.

Venkateswarlu, K. and Shanthi, A. 2012. Formulation and Evaluation of Sustained Release Glipizide Matrix. IOSR J. Pharm. Biol. Sci. 2, 17-23.

United States Pharmacopoeia 24/NF19. 2000. The Official Compendia of Standards. Asian Rockville, M.D. (Ed.), United States Pharmacopoeia Convention Inc, pp. 19131914. 